\title{
CONCEPÇÕES SOBRE A AIDS EM CRIANÇAS
}

\author{
Scheila Tatiana Duarte Cordazzo \\ Universidade Federal de Santa Catarina
}

RESUMO: Esta pesquisa teve como objetivo investigar as concepções das crianças sobre o tema AIDS. Um questionário foi aplicado a 55 crianças de 9 a 12 anos sobre o conhecimento da AIDS, suas causas, prevenção e aproximação com a vida infantil. Os resultados demonstraram que as crianças pesquisadas estão relacionando a AIDS com o sexo. Muitos mitos e preconceitos foram encontrados nas respostas das crianças. Infere-se que os meios de comunicação podem não estar atingindo esta faixa etária através das campanhas preventivas contra a AIDS.

PALAVRAS-CHAVE: AIDS, Crianças, Concepções.

\section{CONCEPTIONS ABOUT AIDS IN CHILDREN}

ABSTRACT: This research investigated the children's conceptions about AIDS. A questionnaire was applied to 55 children from age nine to 12 about their knowledge on AIDS, its cause, prevention and its presence in their daily life. The results showed that the children are making a connection between AIDS and sex. Many myths and preconceptions appeared in the children's answers. We assume that the means of communication have not target this age group on their preventive campaigns against AIDS.

KEY-WORDS: AIDS, Children, Conceptions.

As concepções e definições que circundam os termos saúde e doença abarcam uma série de discussões e interrogações. A começar pela Organização Mundial de Saúde (OMS) que define o termo saúde como uma situação de perfeito bemestar físico, mental e social. Tal definição é vista como ultrapassada e irreal, uma vez que compreende algo inatingível como a perfeição e não leva em consideração as diferentes representações que o termo assume nos diversos pontos do planeta (SEGRE \& FERRAZ, 1997).

As representações sociais sobre os termos saúde e doença se apresentam de formas diferenciadas de acordo com o contexto social e a realidade vivida pelos indivíduos. Entre os adultos existem as aproximações e relações com a incapacidade de trabalhar, com um aspecto externo bom e agradável, com a integração social e até mesmo com a morte (QUEIROZ, 1991). Há também o preconceito que algumas doenças trazem sobre suas vítimas, tais como a AIDS, que geralmente vem carregada de acusações trazidas pela sociedade, que associam a doença à imoralidade e à depravação sexual.

Entre as crianças estas diversidades também existem. Primeiro porque podem estar trazendo isto de sua convivência com adultos, que assim lidam com o tema doença e em segundo lugar por uma série de fatores que acompanham o desenvol- vimento infantil. De acordo com Piaget (1966), a compreensão das crianças sobre saúde e doença está relacionada com o seu desenvolvimento cognitivo. Conforme vai ocorrendo o amadurecimento dos processos cognitivos suas explicações para as possíveis causas da doença vão também se modificando. Papalia e Olds (2000) colocam este processo de modificação da seguinte maneira: $\mathrm{Du}-$ rante a primeira infância e início da segunda, aproximadamente entre os 0 e 4 anos de idade, enquanto a criança está passando por uma fase mais egocêntrica, ela tende a crer que a doença é causada pelas ações próprias, por um comportamento errado ou algo que não deveria ter feito. Após esse período, a criança começa a dirigir a causa da doença para um 'outro' - os germes. Quando começam a se aproximar da adolescência passam a perceber que as doenças podem ter diversas origens, que não são todas exclusivamente causadas por germes, como pensavam anteriormente e que também podem se prevenir de uma série de enfermidades, mantendo-se assim mais saudáveis. Isto gera nos adolescentes um processo de maior atenção ao asseio e cuidado pessoal.

A compreensão das doenças, além de seguir as fases do desenvolvimento infantil também está muito associada a história de vida da criança. A compreensão da origem da gripe, por exemplo, geralmente se dá mais cedo do que as causas 
de outras doenças, o que pode ser explicado pela experiência própria e familiarização com a enfermidade.

Quanto a AIDS, a compreensão das crianças sobre a origem desta geralmente segue a mesma seqüência das fases do desenvolvimento, é o que afirmam Schonfeld, Johnson, Perrin, O'Hare e Cicchetti (1993) em uma pesquisa que realizaram com alunos do jardim de infância até a sexta série. Os pesquisadores constataram que apesar de as crianças estarem dando respostas que pareciam ser corretas, elas não possuíam uma compreensão clara dos processos envolvidos. Por exemplo, a maioria das crianças fez a relação da AIDS com as drogas, entretanto uma grande parte delas parecia desconhecer que o que transmitia a doença era o uso de seringas contaminadas e que o vírus estava no sangue contido nestas seringas.

Quando o assunto foi mais explorado, algumas crianças de segunda série disseram que a transmissão poderia se dar ao passar perto de um usuário de drogas ou de um traficante, trazendo a idéia da disseminação da doença através dos germes que estão próximos a estas pessoas - o que se assemelha a transmissão da gripe (através da aproximação de alguém que está espirrando ou tossindo, pela utilização dos mesmos utensílios, etc). Mesmo havendo tantas campanhas explicativas sobre a AIDS e a sua transmissão, as crianças ainda pensavam desta maneira, o que fez os pesquisadores concluírem que o que falta às crianças jovens não é o conhecimento sobre a doença, mas sim a capacidade de pensar sobre a mesma, coisa que seu nível de desenvolvimento cognitivo ainda não permitia.

Em contrapartida, Papalia e Olds 2000, trazem um experimento realizado com alunos de terceira, quinta e sétima séries, de baixa renda, em escolas americanas. Neste experimento, foram realizadas várias palestras sobre as doenças transmissíveis sexualmente, em especial a AIDS, suas outras formas de transmissão, as conseqüências, os tratamentos, a forma como age no organismo, enfim, foram dados todos os esclarecimentos possíveis sobre a doença em uma linguagem acessível para as determinadas idades das crianças e com recursos, tais como cartazes, que resumiam os pontos mais importantes e chamavam a atenção dos alunos.

Grupos experimentais e de controle foram testados antes de o programa começar e duas semanas depois dele ser concluído. Foi constatado que o grupo que tinha recebido aquela série de informações sabiam muito mais sobre a AIDS do que os grupos que não o tinham recebido. E, que as crianças da terceira série apresentavam os mesmos conhecimentos que as da sétima série. Outra testagem feita um ano depois constatou que os conhecimentos ainda estavam conservados. Tal experimento provou que crianças de diversificadas idades poderiam compreender os mesmos conceitos científicos desde que estes fossem passados da maneira adequada, contrariando assim a teoria de Piaget (1966) que sugere que se a criança não domina um determinado conceito é porque ela ainda não está preparada para isto ou amadurecida para tal.

O objetivo desta explanação não é por a prova as teorias de Piaget, mas sim refletir sobre como as crianças adquirem os conceitos de saúde/ doença (em especial a AIDS), e as variáveis que estão interferindo e agindo neste processo, que poderiam ser sintetizadas como sendo, o meio em que estão inseridas, o contato e a familiarização com a doença, a fase de desenvolvimento e a forma como a instrução é dada.

\section{AIDS: ALGUMAS CONSIDERAÇÕES HISTÓRICAS} E AS PROPORÇÕES DA EPIDEMIA NO BRASIL

A Adquired Immune Deficiency Syndrome (AIDS) ou Síndrome da Imunodeficiência Adquirida (SIDA) é a sigla usada para identificar a doença provocada pelo vírus HIV (Vírus da Imunodeficiência Humana). A AIDS é classificada como uma DST (Doença Sexualmente Transmissível) e foi identificada no início da década de 80 , quando um número elevado de pacientes adultos, do sexo masculino e homossexuais, apresentaram uma série de infecções e comprometimento do sistema imunológico (LIMA, WÜNSSCH, GUITERREZ \& LEITE 1996). A partir daí sua disseminação pelo mundo foi rápida, e o Brasil hoje ocupa o terceiro lugar no mundo em número de casos. As cidades de Balneário Camboriú (SC) e Itajaí (SC) têm o maior número de incidência de casos de AIDS no país (Ministério da Saúde, 2001). No Brasil, existem aproximadamente 223.000 casos de AIDS notificados, entre estes 28.000 são adolescentes e adultos jovens com idades entre 13 e 24 anos (Ministério da Saúde, 2002).

O HIV age diretamente nas células que protegem o corpo das infecções, deixando assim o organismo sem imunidade e exposto a infecções e ao câncer (MONTAGNIER, 1996). O vírus pode ser detectado por uma análise no sangue. $O$ indivíduo portador do vírus HIV não necessariamente desenvolve a AIDS, entretanto ele pode transmitir o vírus a outra pessoa e esta desenvolver a doença.

O HIV mostra-se presente no sangue, no sêmen, na secreção vaginal, na saliva, na urina, 
no leite materno e nas lágrimas. Entretanto, uma pessoa só pode se contaminar através da troca de secreções sexuais pelo ato sexual, anal ou vaginal; por uma transfusão de sangue, pelo uso de agulhas e seringas contaminadas; feridas ou cortes em pele ou mucosas; pela amamentação e pela troca de sangue no cordão umbilical na hora no nascimento (LIMA E COLS, 1996). A AIDS ainda não tem cura. Os tratamentos que hoje existem servem apenas para prolongar o tempo de vida e minimizar os sintomas causados pelas infecções a que o organismo sofre.

Pelo fato da AIDS ter tido seu início entre os homossexuais, os portadores da doença por muito tempo sofreram grandes preconceitos por parte da sociedade. Sociedade esta que criou os chamados grupos de risco, que eram aqueles que viviam na promiscuidade sexual, no uso de drogas e no homossexualismo. Entretanto, a AIDS hoje não representa perigo apenas para estas pessoas, $\mathrm{o}$ grupo de risco não existe mais, pois são muitas as mulheres, crianças e heterossexuais que são os portadores do vírus HIV sem nunca terem pertencido a estes segmentos da sociedade. Hoje em dia, considera-se o termo comportamento de risco.

O Ministério da Saúde junto aos os meios de comunicação e outras organizações tenta alertar a sociedade sobre o risco da AIDS. Várias campanhas são feitas durante o ano. Porém, afirma Jodelet (1998), que estas campanhas muitas vezes têm uma visão limitada, incerta e até contraditória com os conhecimentos e descobertas científicas. Tendo em vista estas afirmações surge a seguinte interrogação: $O$ que as crianças sabem a respeito da AIDS? Desta questão emerge a necessidade de se investigar o conhecimento de crianças a respeito do tema AIDS e seus desdobramentos, como causas, prevenção e a sua proximidade com a vida infantil.

\section{MÉTODO}

Foi aplicado um questionário referentes à AIDS a 55 crianças de nove a 12 anos de idade, sendo que 23 cursavam a $4^{\mathrm{a}}$ série e 33 a $5^{\mathrm{a}}$ série do ensino fundamental em uma escola particular. $\mathrm{O}$ questionário constava de quatro questões sobre AIDS, onde foi solicitado que as crianças respondessem tudo quanto sabiam a respeito do tema. A coleta dos dados foi feita nas salas de aula com aplicação coletiva dos questionários. Os indivíduos não precisavam se identificar, assim poderiam se sentir mais a vontade para escreverem sobre o assunto. As questões eram as seguintes:

1. O que é AIDS?

2. Como se pega AIDS?

\section{Como prevenir a AIDS?}

4. Uma criança pode pegar AIDS? Porquê?

Com as respostas dos questionários foi feita uma análise temática de conteúdo e elaborados gráficos comparativos, afim de se verificar quais são as concepções que as crianças entrevistadas têm a respeito do tema AIDS.

\section{RESULTADOS E DISCUSSÃO}

Após a coleta dos dados foram elaboradas tabelas com os conteúdos e as porcentagens de freqüência das respostas das crianças. Estas tabelas foram transformadas em gráficos comparativos entre as crianças de $4^{a}$ e $5^{a}$ série a fim de se verificar se existem diferenças entre as respostas das crianças das diferentes séries.

Na figura 1 estão explanadas as respostas das crianças sobre a definição de AIDS. As respostas se concentraram em três definições distintas (doença, vírus e não sei). A maioria das crianças, $56 \%$ na $4^{a}$ série e $81 \%$ na $5^{a}$ série definiram a AIDS como uma doença. Outra parcela das crianças responderam ser a AIDS um vírus e $17 \%$ na $4^{\mathrm{a}}$ série e $6 \%$ na $5^{a}$ série responderam não saber o que é AIDS. Mesmo havendo uma série de campanhas explicativas e preventivas ainda encontramos crianças que não sabem definir este termo, o que pode vir ao encontro da teoria de Piaget (1966) que afirma que se a criança ainda não estiver amadurecida para um determinado conceito ela não irá dominálo.

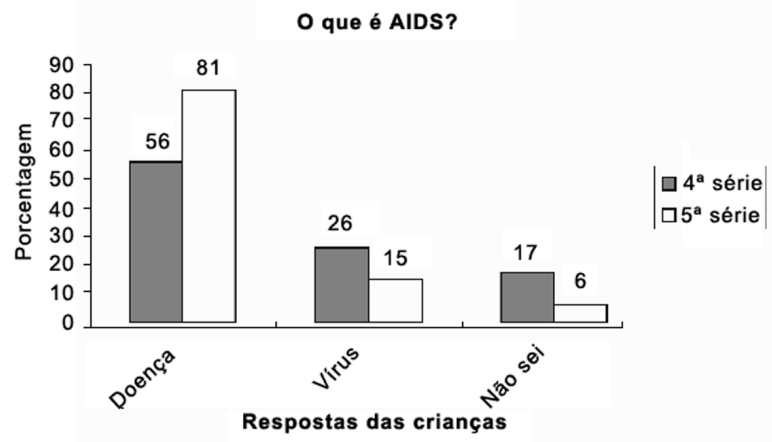

Figura 1 - Respostas das crianças quanto à definição do termo AIDS.

No que se refere as formas de transmissão do vírus (figura 2), a maior parte da turma da $4^{\mathrm{a}}$ série $(56 \%)$ diz não saber como isto se dá. Em contrapartida os alunos da $5^{\mathrm{a}}$ série fazem relação direta da AIDS com o sexo. As respostas sexo, sexo sem camisinha e sexo com contaminado foram classificadas de forma diferenciada, porque os alunos que responderam apenas sexo, podem estar se re- 
ferindo a relação sexual propriamente dita, sem a necessidade da presença de um sujeito contaminado com o vírus HIV. Ainda referente a este item, percebeu-se a existência de alguns mitos e preconceitos referentes as formas de transmissão da AIDS, como por exemplo a contaminação através da piscina, pelo beijo, pela proximidade com alguém infectado, por ratos e pela relação sexual com mais de duas pessoas. Estes temas apareceram com uma freqüência baixa, entretanto merecem atenção, uma vez que reproduzem mitos impostos pela sociedade que trazem preconceitos e sofrimento ao portador da doença.

Outro fator a ser observado é que os alunos da $5^{\text {a }}$ série apresentaram um maior número de mitos em relação à transmissão da AIDS do que os alunos da série anterior. A relação da AIDS com seringas foi feita apenas pelos alunos da $5^{\text {a }}$ série e em número reduzido ( $3 \%$ das respostas). Porém tal dado traz a reflexão se a relação que as crianças fizeram foi com o uso de seringas contaminadas ou com as drogas, uma vez que as crianças apenas citaram seringas como um meio transmissor. Estes resultados vêm ao encontro dos dados encontrados por Schonfeld e cols (1993), onde as crianças não possuíam uma compreensão clara dos processos envolvidos na doença e apenas repetiam frases prontas e jargões utilizados pelos meio de comunicação.

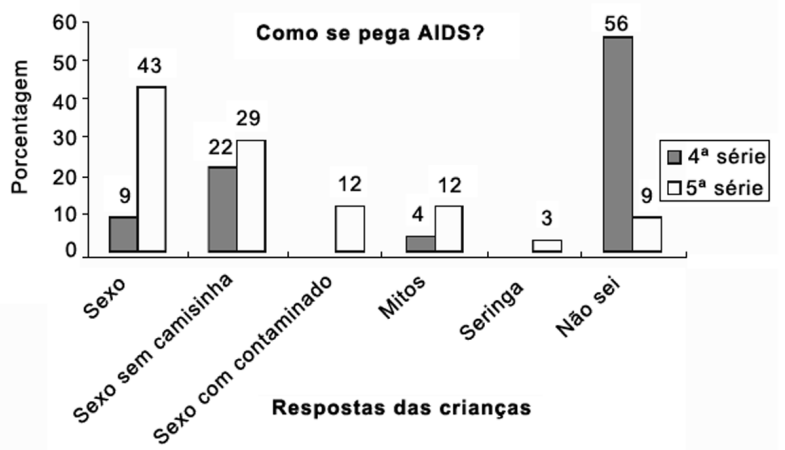

Figura 2 - Respostas das crianças quanto às formas de transmissão da AIDS

No item que se referia às formas de prevenção a palavra "camisinha" merece destaque pois apareceu na maioria dos questionários tanto com os alunos de $4^{\text {a }}$ série (60\%) quanto com os de $5^{\text {a }}$ série (56\%), ver figura 3. Entretanto a seguinte interrogação vem a tona - Os alunos ao citarem a camisinha sabem o porquê e para quê usá-la? Ou isto é apenas uma repetição do que eles ouvem através dos meios de comunicação e campanhas contra a AIDS? O que chamou a atenção é que um dos alu- nos da $4^{a}$ série utilizou um jargão do Ministério da Saúde - "Use Camisinha, todos contra a AIDS". Sendo assim, eles têm realmente conhecimento sobre a importância do uso da camisinha ou estão apenas repetindo frases prontas? Mais uma vez os dados encontrados em Schonfeld e cols (1993) se repetem, pois não se sabe se as crianças têm realmente o conhecimento sobre as formas de prevenção da AIDS.

Nesta questão também apareceram mitos e preconceitos em relação a prevenção à AIDS, entretanto apenas entre os alunos da $5^{\text {a }}$ série. Estes mitos e preconceitos se referiam a (1) não passar perto de alguém contaminado, (2) não fazer sexo, (3) ter relações sexuais apenas com uma pessoa $e$ (4) ir ao médico antes de fazer sexo. Tais afirmações foram consideradas mitos ou preconceitos porque não previnem a contaminação pelo HIV, são informações errôneas pois: (1) O vírus não está no ar para ser transmitido ao passar perto de alguém contaminado; (2) O sexo não é a única forma de transmissão da doença para que se pratique a abstenção deste; (3) Praticar sexo com uma só pessoa não previne contra a AIDS se um dos parceiros estiver contaminado e nenhuma outra medida de prevenção for tomada; (4) Ir ao médico antes de ter relações sexuais pode deixar a pessoa mais informada a respeito dos riscos e formas de prevenção entretanto, se a pessoa não se utilizar dos métodos preventivos pode ficar exposta ao vírus.

Uma parcela das crianças, principalmente da $4^{\mathrm{a}}$ série (35\%), apontou não saber como prevenir a AIDS. Estes dados podem estar confirmando a afirmação de Jodelete (1998) sobre as campanhas contra a AIDS veiculadas nos meios de comunicação e as suas informações limitadas e pouco explicativas.

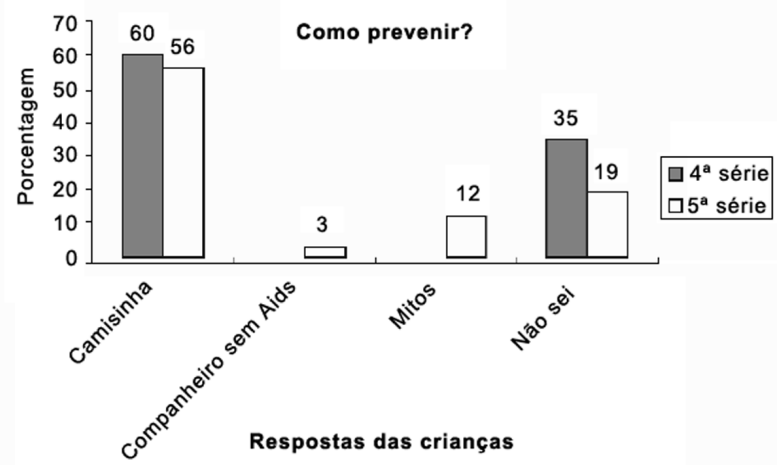

Figura 3 - Respostas das crianças quanto à prevenção da AIDS.

A aproximação das crianças com a doença também foi questionada e as respostas dos alunos, que podem ser visualizadas na figura 4 , se mostra- 
ram um tanto divididas, principalmente com os alunos de $4^{\mathrm{a}}$ série, onde a maioria (52\%), não sabe ou acha que uma criança não pode pegar AIDS. Entre os alunos de $5^{\text {a }}$ série as respostas afirmativas quanto a possibilidade de uma criança vir a ter AIDS foi maior, entretanto o número de respostas não e não sei são expressivas, somando $38 \%$ das respostas da turma. Este pode ser um dado importante para ser considerado, pois não sabendo as formas de prevenção estes indivíduos podem se mostrar vulneráveis às formas de transmissão da doença, tendo em vista que, de acordo com o Ministério da Saúde (2002) grande parte dos infectados no Brasil adquiriram a doença entre os 13 e 24 anos de idade.

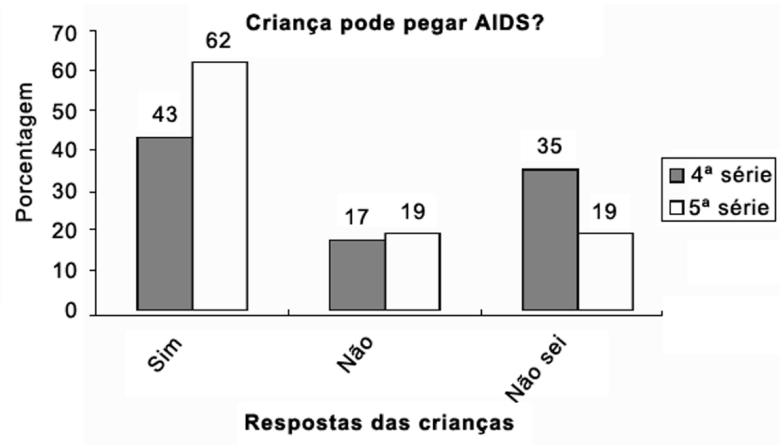

Figura 4 - Respostas das crianças quanto à AIDS na infância.

As justificativas, que podem ser observadas pela tabela 1, apresentaram-se de forma diversificada, sendo que uma parte atribui a contaminação por parte dos pais $\left(9 \%\right.$ na $4^{\text {a }}$ série e $29 \%$ na $5^{a}$ série) e outra parte ao abuso sexual (4\% na $4^{\text {a }}$ série e $9 \%$ na $5^{\mathrm{a}}$ série). Entretanto a maioria das crianças apresentaram respostas diferenciadas e algumas carregadas de preconceitos e mitos, como por exemplo, crianças podem vir a ter AIDS pela simples proximidade com um portador, pelo beijo ou por ratos. Outros justificaram que as crianças não podem ter AIDS respondendo que elas não praticam relações sexuais ou ainda não estão com os órgãos totalmente desenvolvidos.
Tabela 1 - Justificativas sobre as respostas das crianças poderem adquirir AIDS.

\begin{tabular}{l|c|c}
\hline Justificativas & $4^{a}$ série & $5^{a}$ série \\
\hline Pelos pais & $9 \%$ & $29 \%$ \\
\hline Não tem os órgãos formados & $4 \%$ & $12 \%$ \\
\hline Ficar perto de alguém contaminado & $4 \%$ & $3 \%$ \\
\hline Não usar a camisinha & $4 \%$ & - \\
\hline Criança não namora & $4 \%$ & $6 \%$ \\
\hline Abuso sexual & $4 \%$ & $9 \%$ \\
\hline Beijo & - & $6 \%$ \\
\hline Ratos & - & $3 \%$ \\
\hline Seringas & - & $3 \%$ \\
\hline Sexo com contaminado & - & $3 \%$ \\
\hline Pegar em algo que tenha AIDS & - & $3 \%$ \\
\hline Igual ao adulto & - & $3 \%$ \\
\hline Ter contato com sangue contaminado & - & $3 \%$ \\
\hline Não sei & $35 \%$ & $6 \%$ \\
\hline Não responderam & $36 \%$ & $11 \%$ \\
\hline
\end{tabular}

Novamente, a AIDS tem para as crianças uma forte relação com o sexo. Apenas 3\% das crianças da $5^{\text {a }}$ série citaram o uso de seringas, mas não especificaram se estas devem estar contaminadas ou não. A justificativa "pelos pais" teve $9 \%$ entre as crianças da $4^{a}$ série e $29 \%$ entre as da $5^{\text {a }}$ série, entretanto não foi clarificada a maneira pela qual os pais estariam contaminando as crianças, se pelo nascimento, amamentação, ou pelo simples contato. As justificativas apontadas pelas crianças revelaram o pouco conhecimento sobre a AIDS e uma possível situação perigosa, uma vez que a falta de conhecimento pode também expressar falta de prevenção.

\section{CONCLUSÃO}

A partir desta pesquisa, com um grupo reduzido de crianças e pré-adolescentes, pode-se perceber que, mesmo com os meios de comunicação dando relativa ênfase a AIDS e as suas formas de transmissão e de prevenção, este tema ainda parece ser uma incógnita para o grupo pesquisado, que expressou através de suas respostas muitas dúvidas e preconceitos quanto ao tema AIDS.

As dúvidas ficam evidentes quando eles respondem que não sabem como esta é transmitida, como é prevenida ou até mesmo o que seja a AIDS. Os mitos e preconceitos dizem respeito a proximidade com um portador, a transmissão pela saliva, através do beijo, ou pela piscina, mitos estes que já foram comprovados como sendo falsos.

Portanto pode-se inferir que, os meios de comunicação ao divulgarem as campanhas contra a AIDS não estão atingindo esta faixa etária e as crianças estão chegando à adolescência sem terem muito conhecimento da AIDS. Estes dados são 
Cordazzo, S.T.D. "Concepções sobre a AIDS em crianças"

relevantes para a elaboração de estratégias de prevenção, tendo em vista que as primeiras experiências sexuais se dão freqüentemente na adolescência. Com estes dados observa-se a necessidade de campanhas preventivas que estejam de acordo com os níveis de desenvolvimento cognitivo e emocional das crianças e pré-adolescentes, para assim poderem atingir estas camadas da sociedade e alertálas do perigo que a AIDS representa para elas

\section{REFERÊNCIAS}

BRASIL. Ministério da Saúde. Boletim epidemiológico - AIDS - Julho à Setembro de 2001: Sistema nacional de notificação. Brasília: 2001, Coordenação Nacional de DST e AIDS. Disponível em: www.aids.gov.br. Data do acesso: fevereiro de 2002.

BRASIL. Ministério da Saúde. AIDS: etiologia, clínica, diagnóstico e tratamento. Brasília: 2002, Unidade de assistência. Disponível em: www.aids.gov.br. Data do acesso: fevereiro de 2002.

JODELET, D. Representações do contágio e a AIDS. (M. Madeira \& R. Carvalho, Trad.). In: MADEIRA, M.; JODELET, D. (Orgs.). AIDS e representações sociais: À busca de sentidos. Natal: EDUFRN, 1998.

LIMA, A. L.; WÜNSCH, C. T.; GUITERREZ, E. B.; LEITE, R. M. Epidemiologia. In: LIMA, A. L. (Org.). HIV/AIDS: Perguntas e respostas. São Paulo: Editora Atheneu, 1996.

MONTAGNIER. L. SIDA: Factos/Esperanças. 10 ed. França: Instituto Pasteur, 1996.

PAPALIA, D. E.; OLDS, S. W. Desenvolvimento Humano. Trad. Daniel Bueno. $7^{\mathrm{a}}$ edição. Porto Alegre: Artes Médicas, 2000.

PIAGET, J. O nascimento da inteligência na criança. Rio de Janeiro: Zahar, 1966.

QUEIROZ, M. de S. Representações sobre saúde e doença: Agentes de cura e pacientes no contexto do SUDS. Campinas: Editora da UNICAMP, 1991.

SCHONFELD; JOHNSON; PERRIN; O'HARE; CICCHETTI. Understanding of acquired immunodeficiency syndrome by elementary school children: A developmental survey. Pediatrics, Yale, v. 2, p. 389-395, 1993.
SEGRE, M.; FERRAZ, F.C. O conceito de saúde. Revista de Saúde Pública, São Paulo, v. 31, n. 5, p. 1-8, 1997.

Scheila Tatiana Duarte Cordazzo é Psicóloga Clínica e Escolar - Mestre em Psicologia pela UFSC $O$ endereço eletrônico da autora é : scheila.tati@bol.com.br

\section{Sheila Tatiana Cordazzo Concepções do termo AIDS entre crianças Recebido: 28/05/2004 $1^{\mathrm{a}}$ revisão: 27/08/2004 $2^{\mathrm{a}}$ revisão: 7/12/2004 Aceite final: 14/12/2004}

